uncovered only one similar case report. (Sankararaman S, Riel-Romero RMS, GonzalezToledo E. Brain abscess from a peritonsillar abscess in an immunocompetent child: A case report and review of the literature. Pediatr Neurol 2012 Dec;47(6):451-4). (Response: Dr Sankararaman; E-Mail: drsskumar@gmail.com).

COMMENT. Predisposing risk factors for pediatric brain abscess include congenital cyanotic heart disease, immunocompromised state, or septic foci in teeth, paranasal sinuses, middle ear, mastoid and tonsils. Cranial MRI in diagnosis of suspected brain abscess should include a possible source of infection in sections of the neck.

\title{
AAN GUIDELINE ON STEROIDS AND ANTIVIRALS FOR BELL PALSY
}

The Guideline Development Subcommittee of the AAN provides an update of the 2001 evidence-based practice guideline for the treatment of Bell palsy. A search of Medline and the Cochrane Database of Controlled Clinical Trials for articles published since January 2000 identified 9 studies (2 rated Class I) of patients with new-onset Bell palsy who received steroids/antiviral agents. The committee concludes as follows: 1) Steroids are highly likely to be effective and should be offered to increase the probability of recovery of facial nerve function; 2) antiviral agents in combination with steroids do not increase the probability of facial functional recovery by $>7 \%$. Antivirals may be offered in addition to steroids because of a possible modest increase in recovery, but patients should be counseled that a benefit from antivirals has not been established. (Gronseth GS, Paduga R. Evidence-based guideline update: steroids and antivirals for Bell palsy. Report of the Guideline Development Subcommittee of the American Academy of Neurology. Neurology 2012 Nov 27;79(22):2209-13). (Response and reprints: American Academy of Neurology. E-mail: guidelines@aan.com).

COMMENT. The committee suggests for further research, large randomized trials comparing outcomes after steroids with or without antivirals, including patients with zoster sine herpete. The optimal dose and timing of steroids and their effects in children should be determined.

\section{MOVEMENT DISORDERS}

\section{THALAMIC METABOLISM AND RESTLESS LEGS SYNDROME}

Researchers at University of Bologna, Italy, evaluated medial thalamus metabolism and structural integrity in 23 patients with restless legs syndrome and 19 healthy controls. Proton magnetic resonance spectroscopy (PMRS) disclosed a significantly reduced N-acetylaspartate creatine ratio and N-acetylaspartate concentrations in the medial thalamus of patients with restless legs syndrome compared to controls $(\mathrm{P}<0.01)$. Lower $\mathrm{N}$-acetylaspartate concentrations were significantly associated with a family history of restless legs syndrome $(\mathrm{P}=0.018)$. Dysfunction of the medial thalamus and limbic system plays a role in the pathophysiology of idiopathic restless legs syndrome. In contrast, thalamic volume studies using diffusion tensor imaging, and voxel-based morphometry showed no structural thalamic changes. (Rizzo 
G, Tonon C, Testa $\mathrm{C}$, et al. Abnormal medial thalamic metabolism in patients with idiopathic restless legs syndrome. Brain 2012 Dec;135(Pt 12):3712-20). (Respond: Raffaele Lodi MD, PhD. E-mail: raffaele.lodi@unibo.it).

COMMENT. RLS is heterogeneous, some cases symptomatic of iron deficiency, uremia, pregnancy and polyneuropathy, and others idiopathic, especially patients with onset before age 30 years. Genetic risk variants have also been identified. (Paulus W, et al. Update of the pathophysiology of the restless-legs-syndrome. Mov Disord 2007;22 Suppl 18:S431-9).

Investigation of unmedicated early onset restless legs syndrome by voxel-based morphometry, T2 relaxometry, and functional MR imaging during the night-time hours reveals no regional brain volume changes but indicates increased iron content in the globus pallidus and substantia nigra, suggesting dysfunction of the basal ganglia. Activation of the striatofrontolimbic area may represent the neurofunctional substrate mediating RLS. (Margariti PN, et al. AJNR Am J Neuroradiol 2012 Apr;33(4):667-72).

\section{HEMI-CHOREA AND BRAINSTEM GLIOMA}

A case-report from Baroda Medical College, India, concerns a 9-year-old girl who complained of difficulty in walking and involuntary movements of the left upper and lower limbs. On neurological examination she had chorea involving the left side, bilateral lateral rectus palsy, and spasticity of the right upper and lower limbs. CT scan and MRI showed a focal glioma involving the upper pons and midbrain. Following surgery for removal of the tumor, hemi-chorea decreased in intensity. Histopathological examination showed a pilocystic astrocytoma grade 1. (Patankar AP. Hemi-chorea: an unusual presentation of brainstem glioma. Br J Neurosurg 2012 Nov 21. [Epub ahead of print]). (Response: Dr Patankar, Baroda Medical College, Vadodara, Gujarat, India).

COMMENT. Brain tumor is an unusual cause of extrapyramidal signs and symptoms. In children treated at the Mayo Clinic between 1950 and 1960, 4\% of brain tumors involved the basal ganglia but $<1 \%$ were associated with involuntary movements. In a report of 2 children, ages 6 and 12 years, presenting with choreiform movements and dystonia, the tumor involved the right thalamus in one and was caudad to the thalamus, in the mesencephalon and upper pons, in the other. (Millichap JG, et al. JAMA 1962 Feb 24;179:589-93). The localization of the lesion involved with involuntary movements often shows discrepancies, and only lesions in the subthalamic nucleus of Luys are attended by a consistent clinical disorder, usually a contralateral hemichorea or hemiballism. (Denny-Brown D, Christian HA. Diseases of Basal Ganglia and Subthalamic Nuclei. New York: Oxford University Press; 1946. p. 261). Tumor as a cause of choreiform disorder should be considered when the involuntary movements are progressive and are associated with cranial nerve lesions and crossed hemiparesis and/or ataxia. (Ropper AH, Adams RD, Victor M, Samuels MA, Eds. Adams and Victor's Principles of Neurology. 9th ed. New York: McGraw-Hill Medical; 2009). 